(but, strangely, not of selerotia), and of the fruit bodies of higher fungi. The genetics and classification of fungi are introduced in general terms with a brief historical review, and the account proceeds via nuclear division to genetic mechanisms including nuclear fusion, heterothallism, dikaryosis, heterokaryosis and a mention of the parasexual cycle. The breakdown of simple and more complex tissues by fungi, and the part played by bacteria, are discussed, as is the role of nitrogen in these processes.

The strength of the book comes in the second part, beginning with a critical account of the main techniques which have been used to isolate fungi from the soil, and proceeding to the distribution of organic matter within the soil, and the factors which affect fungal colonization and succession on the substrate. The practical applications of such investigations lead directly to a discussion of saprophytic competition in the soil. The last chapter is devoted to root-infecting fungi which are placed in one of three groups: primitive or specialized parasites, and mycorrhizal fungi, with a lucid account of the characteristics of each group.

The book is well documented, with 124 references and a short list of books for general reading at the end of the second chapter; the index is perfectly adequate. It is well produced, and is illustrated by two plates and fourteen text figures. It is bound in a soft 'flexicover'.

In a short book, when so much has to be omitted, it is not always possible to qualify all the generalizations which are made. At times this is unfortunate, and oceasionally misleading, as on p. 49 where reference is made to the sperm and tho egg in higher plants and animals, and on p. 28 where the yeasts are included with the Oomycetes as having cellulose cell walls as in higher plants. Certainly this is known to be the case for some of the Oomycetes, but the yeasts have been stated to possess a polyglucose wall which is distinct from cellulose. While it is obvious that Dr. Garrett means that simple carbohydrates are formed at first in photosynthesis, the use, on p. 22, of the formula $\mathrm{CH}_{2} \mathrm{O}$ could be misleading to the beginner, as could the remark on p. 70 that "woody stems will absorb nitrogen from the surrounding soil during decomposition".

Newcomers to biology will find the early chapters an interesting introduction to the subject, while young biologists will find the approach refreshing. All students of soil mycology will benefit from reading tho later chapters, where the essence of Dr. Garrett's vast research experience is evident. Few will fail to be fascinated by seeing the evolution of a field of research, or by the glimpses of research problems and the detailed thoughtprocesses which go into solving them. Such readers, while able to appreciate Dr. Garrett's concern for the beginner, may well regret that these later chapters were not expanded to fill a whole book.

G. J. F. Pugh

\section{TICKS IN BRITAIN}

British Ticks

By Prof. Don R. Arthur. Pp. ix +213. (London: Butterworth and Co. (Publishers), Ltd., 1963.) 558.

A CCORDING to the author, "ticks are the most impor. A tant arthropod vectors of disease to domestic animals [in Britain], and probably the least well known". There are apparently twenty-two species of British ticks, and "the main purpose of this book is to assist in recognition. [that is, identification] of the British species and to gather between two covers such sources of biological information as are available".

The first part of the author's purpose is accomplished with monumental thoroughness. Indeed, no less than three-quarters of the book is devoted to identification under the following headings: techniques and terms; keys to families, to genora, and to the males, females, nymphs and larva of the species; descriptions of the species.
The exposition of techniques is lucid but, in a book otherwise characterized by excellently clear drawings, it is exasperating to find that a magnifying glass is required to reveal details in the basic diagrams of male and female (Figs. 1-4) illustrating the anatomical terms used in the keys. These diagrams should be twice as large and shorn of their obfuscating covering of hairs. So far as could be ascertained by running down a limited amount of preserved material, the keys themselves seem admirable. A minor fault is the failure to indicate absence of $I$. pari in the key to the males, and of both $I$. arvicolae and $I$. guernseyensis in the key to the nymphs, of the genus Ixodes.

The descriptions of species, although equally lucid, are invariably cluttered with futile measurements of a "type specimen' in the antique taxonomic tradition. As a typical oxample, the female of Ixodes ricinus is stated to have the following dimensions (length $\times$ breadth or length alone) in $\mathrm{mm}$; capitulum $1.0 \times 0.59$; palp, segment 2 , $0.37 \times 0.23$, and segment $3,0.32$; tarsus $I, 0.76$, and IV, $0 \cdot 61$; metatarsus I, $0 \cdot 40$, and IV, $0 \cdot 38$. The inclusion of such data unfortunately suggests lack of appreciation that dimensions of bodily parts. and ratios thereof, vary considerably within any species. Incidentally, six of the twenty-two species are incompletely described, five (genus Ixodes) unavoidably because male and/or young stages are "unavailable" or "not known", and one (Hyalomma aegyptium) for no stated reason since its nymph and larva are simply not mentioned.

In accordance with the second part of the author's purpose, biological information is provided at the end of the description of each species under the following headings: distribution; hosts; biology and ecology; disease relationships. Here the accomplishment is less satisfactory.

More often than not, British records of distribution aro sandwiched within a tedious, higgledy-piggledy list of "selected" (see p. ix) European or world records with no explanation of the mode or intention of the selection. In a book devoted to British ticks, one would expect to have first the full details for Britain and then no more than a bare list of the foreign countries in which the species occurs. Again, there really is no need to give complete lists of known hosts in other countries. The only foreign records of interest in this kind of book are those for animals which either have not so far been recorded as hosts in Britain or (loss important) do not occur in Britain.

The sections dealing with biology and ecology are the least satisfactory of all. The author seems undecided as to what is biology and what ecology. Thus, for example, the very scanty information on Ixodes festai is apportioned to two sections respectively entitled "Biology" and "Ecology", while the same kinds of information on $I$. ricinus are bundled into a single section entitled "Biology". This must seem even more ourious to readers who know that 1 . ricinus is the only British tick with its ecology fully worked out. Moreover, in the few species where the available range of information is fairly wide, the choice of, and emphasis on, topics seems to be capricious. Thus, for example, there is undue preoccupation with feeding and moulting in $I$. hexagonus and with seasonal activity in I. ricinus. The book would be much improved by reducing the text here to a brief statement of (1) seasonal incidence of host infestation; (2) time required for engorgement; (3) habitat off the host; (4) references to papers providing fuller biological/ecological information.

The authorities for statements on diseaso relationships are too often omitted in the text.

Despite the foregoing criticisms, this is undoubtedly a very valuable reference book on British ticks because it facilitates identification and lists all the relevant biological papers. Anyone who (like myself) has struggled with the world-embracing taxonomic monograph of Nuttall et al. and the scattered literature will gladly endorse this opinion.

A. Mirne 